\title{
Serum $\beta$-2 microglobulin levels are associated with distant metastasis in patients with breast cancer
}

\author{
SORRASIT JONGVILAIKASEM ${ }^{1}$, SRILA SAMPAO ${ }^{1}$, KANET KANJANAPRADIT ${ }^{2}$, \\ JIRAKRIT SAETANG $^{1,3}$, SURASAK SANGKHATHAT ${ }^{1,4}$ and SOMRIT MAHATTANOBON ${ }^{1}$
}

\author{
Departments of ${ }^{1}$ Surgery and ${ }^{2}$ Pathology; ${ }^{3}$ EZ-Mol-Design Laboratory; ${ }^{4}$ Translational Medicine Research Center, \\ Faculty of Medicine, Prince of Songkla University, Hat Yai, Songkhla 90110, Thailand
}

Received October 26, 2020; Accepted February 24, 2021

DOI: $10.3892 / \mathrm{mco} .2021 .2280$

\begin{abstract}
Serum $\beta$-2 microglobulin ( $\beta 2-\mathrm{M})$ levels have been identified to be higher in patients with cancer than in healthy individuals. The aim of the present study was to evaluate the association between serum $\beta 2-\mathrm{M}$ levels and clinicopathological characteristics of patients with breast cancer in a prospective cohort study, and to evaluate the effect of $\beta 2-\mathrm{M}$ on cancer cell migration in vitro. Serum samples from 200 female patients with histologically confirmed invasive breast cancer were collected between 2017 and 2019. Their clinicopathological information was obtained and analyzed. The $\beta 2-\mathrm{M}$ levels were identified to be associated with age, histologic subtype and metastatic status. When the diagnostic association of $\beta 2-\mathrm{M}$ and metastatic status was analyzed, the area under the receiver operating characteristic curve was 0.78 . Using a cut-off serum $\beta 2-\mathrm{M}$ level of $1.9 \mu \mathrm{g} / \mathrm{ml}$, the sensitivity for diagnosing metastatic status was $87.5 \%$, the specificity was $65.0 \%$, and the diagnostic odds ratio was 2.47 . Upon age stratification, the association between the $\beta 2-\mathrm{M}$ level and metastatic status was significant only in the group aged $>55$ years. In survival analysis, $\beta 2-\mathrm{M}$ levels $>1.9 \mu \mathrm{g} / \mathrm{ml}$ were associated with a poor survival outcome. In vitro, the MCF-7 breast cancer cell line exhibited increased cellular migration following treatment with $30 \mu \mathrm{g} / \mathrm{ml} \beta 2-\mathrm{M}$. Serum $\beta 2-\mathrm{M}$ may be a predictor of metastatic status in breast cancer.
\end{abstract}

\section{Introduction}

Breast cancer is the most common site-specific cancer and the leading cause of cancer-related death in women aged 20 to 39 years (1). The disease is a current global health problem, and more than 1 million cases are newly diagnosed each

Correspondence to: Dr Somrit Mahattanobon, Department of Surgery, Faculty of Medicine, Prince of Songkla University, 15 Karnjanavanich Road, Hat Yai, Songkhla 90110, Thailand

E-mail: msomrit@medicine.psu.ac.th

Key words: breast cancer, $\beta-2$ microglobulin, metastasis, biomarker, MCF-7 year (2). It is estimated that 1 in 8 of women in the United States $(12.4 \%)$ is affected by invasive breast cancer in their lifetime (3). Moreover, in 2018, approximately 64,000 woman were diagnosed with in situ breast cancer, and approximately 41 thousand of women in the US died from this disease (4). However, approximately $50 \%$ of breast cancer incidence globally and $60 \%$ of breast cancer mortality occur in middle- to low-income countries, including Thailand, where the age-standardized incidence of breast cancer was 28.5 per 100,000 from 2010 to 2012 (2,5). Currently, strategies for breast cancer diagnosis include imaging and pathological studies, and clinicopathological aspects such as tumor size, TNM stage, hormone receptor status, and molecular subtype are used for therapeutic planning and prognostication (6).

$\beta 2$-microglobulin $(\beta 2-\mathrm{M})$ is a low-molecular-weight protein consisting of a single chain of 100 amino acids that is a part of the invariant light chain of the HLA antigen molecule $(7,8)$. It is expressed on the membrane of almost all nucleated cells and is detectable in all body fluids as a shedding product of cell membranes $(9,10)$. Ninety percent of $\beta 2-\mathrm{M}$ is eliminated through glomerular filtration and is almost completely reabsorbed by the proximal convoluting tubules. At the clinical level, serum and urine $\beta 2-\mathrm{M}$ concentrations are used to monitor glomerular and tubular nephropathies $(11,12)$. The levels of serum and urine $\beta 2-\mathrm{M}$ are also increased in patients with neoplastic diseases, including multiple myeloma, lymphoma and leukemia (13-16). Increased serum $\beta 2-\mathrm{M}$ levels reflect increased cellular turnover rate and disease progression in some hematologic malignancies $(17,18)$. For example, a $\beta 2-\mathrm{M}$ value of less than $4 \mu \mathrm{g} / \mathrm{ml}$ was found to correlate with better survival in multiple myeloma (19). Increased $\beta 2-\mathrm{M}$ serum levels in patients with breast cancer has been reported $(20,21)$. An immunohistochemical (IHC) study reported that serum $\beta 2$-microglobulin levels in patients with breast cancers were significantly higher than those in patients with benign breast tumors. In addition, the expression levels of $\beta 2-\mathrm{M}$ protein in breast cancer tissue were found to be significantly different among patients with the 4 molecular subtypes $(22,23)$. However, the clinical value of serum $\beta 2-\mathrm{M}$ as a prognostic marker and predictor of survival needs further study (24).

The aim of this study was to evaluate the association between serum $\beta 2-\mathrm{M}$ levels and the clinicopathological characteristics of breast cancer patients, especially the intrinsic 
subtypes and clinical stages. In addition, an in vitro study of the influence of $\beta 2-\mathrm{M}$ on the cellular migration of a breast cancer cell line was conducted.

\section{Materials and methods}

Subjects and study protocols. The study design was a prospective cohort. Serum samples from a total of 200 female patients with histologically confirmed invasive breast cancer at Songklanagarind Hospital and adequate pathological data were collected from 2017 to 2019 after informed consent was obtained. The exclusion criteria included those with abnormal renal function, those who had previously received any form of treatment for breast cancer and those with other cancers. Pathologic stage and cancer subtype were identified according to the AJCC 8th Edition (25) and St. Gallen International Expert Consensus 2013 (26), respectively. Metastatic work-up included abdominal ultrasound and chest computerized tomography. The metastatic status of all patients was confirmed by radiology and histopathological evidence. Treatment of breast cancer in our institute followed the Adult Cancer Treatment Guideline of Thai National Health Security Office (2018) with individual adjustment according to the functional status. Patients were appointed every 3 months during the period of active treatment, then every 6 months, thereafter. The Human Research Ethics Committee of the Faculty of Medicine, Prince of Songkla University, approved the study protocol (Reference no. 60-040-10-1).

Serum $\beta 2-M$. Serum $\beta 2-\mathrm{M}$ level was measured once at the time of breast cancer diagnosis. Blood was collected under aseptic precautions. Serum was separated and immediately analyzed by immunological agglutination with latex reaction enhancement assay using Immunoturbidimetric Assay kit (Roche/Hitachi). The ratio of reaction is 2:180:80 for sample:buffer:latex suspension. The concentration of $\beta 2$-microglobulin was evaluated by measuring the agglutination reaction at $570 \mathrm{~nm}$ compared to the absorbance of standard $\beta 2$-microglobulin.

IHC staining. The expression of ER, PR, HER-2 and Ki67 in tumor tissues was evaluated by IHC staining with the following primary antibodies: Anti-ER (Thermo Scientific, Inc., clone SP1, 1/250 dilution), anti-PR (Leica Biosystems, 1/2500 dilution), anti-Ki-67 antigen (Dako Glostrup, 1/250 dilution), and anti-HER2 (Ventana). The staining results were reported by a certified pathologist as the number of positive cells per 100 cancer cells. In cases with equivocal HER2 results, the specimens were further studied by HER-2 dual in situ hybridization (HER2-DISH).

HER2-DISH. HER2 and chromosome 17 probes were used for two-colour chromogenic in situ hybridization of formalin-fixed paraffin-embedded human breast cancer specimens following the VENTANA BenchMark XT automated slide staining protocol. The slides were evaluated under light microscopy for HER2 and chromosome 17 signals in at least 20 nuclei. Calculation of the HER2/chromosome 17 ratio was performed by dividing the total number of HER2 signals in the target area by the total number of chromosome 17 signals in the same area.
Cell migration assay. The cell migration assay was conducted in a 24-well plate with Transwell chambers $(8-\mu \mathrm{m}$ pore PET membrane; Falcon, Fisher Scientific). The low migratory cell line, MCF-7, obtained from American Type Culture Collection (ATCC; Catalog HTB-2), and routinely cultured on monolayers at $\leq 80 \%$ confluence in RPMI-1640 medium (Gibco) containing $10 \% \mathrm{FBS}$ at $37^{\circ} \mathrm{C}, 5 \% \mathrm{CO}_{2}$ was used in this study. After starvation for $24 \mathrm{~h}, 2 \times 10^{5}$ cells in $100 \mu 11 \%$ FBS RPMI-1640 medium with or without recombinant $\beta 2$-microglobulin (Abcam) were added to the upper compartment of the chamber, whereas the lower chamber contained RPMI-1640 with 10\% FBS. After $72 \mathrm{~h}$ of incubation at $37^{\circ} \mathrm{C}$, the cells on the upper surface were removed using a cotton swab. The membranes were fixed with $70 \%$ ethanol for $10 \mathrm{~min}$ at room temperature and stained with $0.1 \%$ crystal violet for $10 \mathrm{~min}$. The number of migrated cells was quantified by counting cells in five different fields of view under a light microscope at a magnification of 200x. The data are presented as the mean $\pm \mathrm{SD}$.

Statistical analysis. The association between $\beta 2-\mathrm{M}$ levels and clinicopathological factors was analyzed by using unpaired Student's t-test or one-way ANOVA with Tukey's post hoc test. As age at diagnosis was a major confounder, patients were subcategorized into 2 groups on the basis of age, those aged 25-55 years and those aged $>55$ years, for analysis of the association between metastatic status and $\beta 2-\mathrm{M}$ level. For the Transwell migration study, one-way ANOVA followed by Turkey's post hoc test was used to determine statistical significance between groups. A receiver operating characteristic (ROC) curve was plotted using the sensitivity and specificity of each $\beta 2-\mathrm{M}$ cut-off that predicted metastatic status. Survival analysis used log rank test and Kaplan-Meier survival plot with cancer related death used as a censor in overall survival (OS) analysis. Beginning date used operative date and survival data were as of December 2020. All data were analyzed with Statistical Package Stata 14.0 (Stata Corporation). A P-value of less than 0.05 was considered statistically significant.

\section{Results}

Patients and clinical data. A total of 200 patients were included in this study. The mean age at the time of diagnosis was 54 years (range 25-88 years). The most common histological type was invasive ductal carcinoma (188 cases; 94\%), where the most frequent tumor grade was grade III (83 cases; $41.5 \%$ ). The percentage of patients with positive lymphovascular invasion was $36.5 \%$ (73 cases). Lymph node involvement was most frequently seen in the N0 group (121 cases; 60.5\%). $\mathrm{T} 2$ was the highest group among the $\mathrm{T}$ stages (108 cases; $54 \%$ ). The percentage of patients with distant metastasis was $4 \%$ (8 cases). Regarding tumor molecular subtypes, luminal B was the most common tumor subtype, followed by luminal A (Table I). The example of HER-2 staining and HER-2-DISH was showed as Fig. S1.

$\beta 2-M$ levels were associated with metastatic status and survival rate in breast cancer patients. The serum $\beta 2-\mathrm{M}$ levels in female breast cancer patients according to each pathological parameter are shown in Table I. Statistically significant 
Table I. Serum $\beta 2-\mathrm{M}$ levels in patients with breast cancer according to pathological parameters.

\begin{tabular}{|c|c|c|c|}
\hline Variable & No. $(\%)$ & $\begin{array}{c}\text { Average } \beta 2-\mathrm{M}, \\
\mu \mathrm{g} / \mathrm{ml} \text { (range) }\end{array}$ & P-value \\
\hline Total cases & $200(100.0)$ & $1.83(0.5-4.2)$ & \\
\hline Age, years & & & $<0.01^{\mathrm{a}}$ \\
\hline $0-55$ & $110(55.0)$ & $1.64(0.5-4.0)$ & \\
\hline$>55$ & $90(45.0)$ & $2.05(0.9-4.2)$ & \\
\hline Tumor side & & & $0.70^{\mathrm{a}}$ \\
\hline Right & $101(50.5)$ & $1.84(1.0-4.2)$ & \\
\hline Left & 99 (49.5) & $1.81(0.5-4.0)$ & \\
\hline Histologic type & & & $0.02^{\mathrm{a}}$ \\
\hline Invasive ductal carcinoma & $188(94.0)$ & $1.80(0.5-4.2)$ & \\
\hline Lobular carcinoma and others & $12(6.0)$ & $2.21(1.9-2.5)$ & \\
\hline Tumor grade & & & $0.41^{\mathrm{b}}$ \\
\hline Grade-1 & $36(18.0)$ & $1.79(1.0-3.8)$ & \\
\hline Grade-2 & $81(40.5)$ & $1.89(1.1-4.0)$ & \\
\hline Grade-3 & $83(41.5)$ & $1.77(0.5-4.2)$ & \\
\hline Lymphovascular invasion & & & $0.54^{\mathrm{a}}$ \\
\hline No & $127(63.5)$ & $1.84(0.9-4.2)$ & \\
\hline Yes & $73(36.5)$ & $1.79(0.5-4.0)$ & \\
\hline T-stage & & & $0.17^{\mathrm{b}}$ \\
\hline $\mathrm{T} 1$ & $75(37.5)$ & $1.79(1-3.8)$ & \\
\hline $\mathrm{T} 2$ & $108(54.0)$ & $1.81(0.5-4)$ & \\
\hline $\mathrm{T} 3$ & $9(4.5)$ & $2.26(1.3-4.2)$ & \\
\hline $\mathrm{T} 4$ & $8(4.0)$ & $1.79(1.3-2.3)$ & \\
\hline N-stage & & & $0.72^{b}$ \\
\hline N0 & $121(60.5)$ & $1.85(0.9-4.0)$ & \\
\hline N1 & $52(26.0)$ & $1.83(0.5-4.2)$ & \\
\hline $\mathrm{N} 2$ & $18(9.0)$ & $1.71(1.3-2.5)$ & \\
\hline N3 & $9(4.5)$ & $1.71(1.2-2.1)$ & \\
\hline M-stage & & & $<0.01^{\mathrm{a}}$ \\
\hline M0 & $192(96.0)$ & $1.80(0.5-4.0)$ & \\
\hline M1 & $8(4.0)$ & $2.40(1.4-4.2)$ & \\
\hline Clinical stage & & & $0.15^{\mathrm{b}}$ \\
\hline Stage 1 & $58(29.0)$ & $1.83(1.0-3.8)$ & \\
\hline Stage 2 & $104(52.0)$ & $1.81(0.5-4.0)$ & \\
\hline Stage 3 & $30(15.0)$ & $1.70(1.2-3.1)$ & \\
\hline Stage 4 & $8(4.0)$ & $2.40(1.4-4.2)$ & \\
\hline ER status & & & $0.75^{\mathrm{a}}$ \\
\hline Negative & $42(21.0)$ & $1.80(0.9-4.0)$ & \\
\hline Positive & $158(79.0)$ & $1.83(0.5-4.2)$ & \\
\hline PR status & & & $0.74^{\mathrm{a}}$ \\
\hline Negative & $68(34.0)$ & $1.84(0.9-4.2)$ & \\
\hline Positive & $132(66.0)$ & $1.81(0.5-4.0)$ & \\
\hline HER2 status & & & $0.71^{\mathrm{b}}$ \\
\hline Negative & $133(66.5)$ & $1.82(0.5-4.0)$ & \\
\hline Equivocal & $22(11.0)$ & $1.92(1.3-3.3)$ & \\
\hline Positive & $45(22.5)$ & $1.81(0.9-4.2)$ & \\
\hline Intrinsic subtype & & & $0.54^{\mathrm{b}}$ \\
\hline Luminal A & $78(39.0)$ & $1.77(0.5-4.0)$ & \\
\hline Luminal B & $88(44.0)$ & $1.89(0.9-4.2)$ & \\
\hline HER-2 & $18(9.0)$ & $1.72(0.9-2.6)$ & \\
\hline Triple negative & $24(12.0)$ & $1.85(1.2-4.0)$ & \\
\hline
\end{tabular}

${ }^{\mathrm{a} C}$ Comparisons of $\beta 2-\mathrm{M}$ between subgroups were performed using an unpaired Student's t-test. ${ }^{\mathrm{b}}$ Comparisons of $\beta 2$-M among subgroups were performed using one-way ANOVA. $\beta 2-\mathrm{M}, \beta-2$ microglobulin; ER, estrogen receptor; PR, progesterone receptor. 
Table II. Comparing serum $\beta 2-\mathrm{M}$ levels stratified by age group.

$\beta 2-\mathrm{M}$ levels in no metastasis

Age group group, $\mu \mathrm{g} / \mathrm{ml}$ $\beta 2-\mathrm{M}$ levels in metastasis

group, $\mu \mathrm{g} / \mathrm{ml}$
P-value

\begin{tabular}{llll}
\hline $25-55$ years $(\mathrm{N} \mathrm{106:4)}$ & 1.63 & 1.98 & 0.14 \\
$>55$ years $(\mathrm{N} \mathrm{86:4)}$ & 2.01 & 2.82 & 0.01 \\
\hline
\end{tabular}

${ }^{a}$ Comparison was made using Student's t-test (unpaired; two-sided). $\mathrm{N}$ represents the number of cases in the non-metastasis group:number of cases in the metastasis group. $\beta 2-\mathrm{M}, \beta-2$ microglobulin.

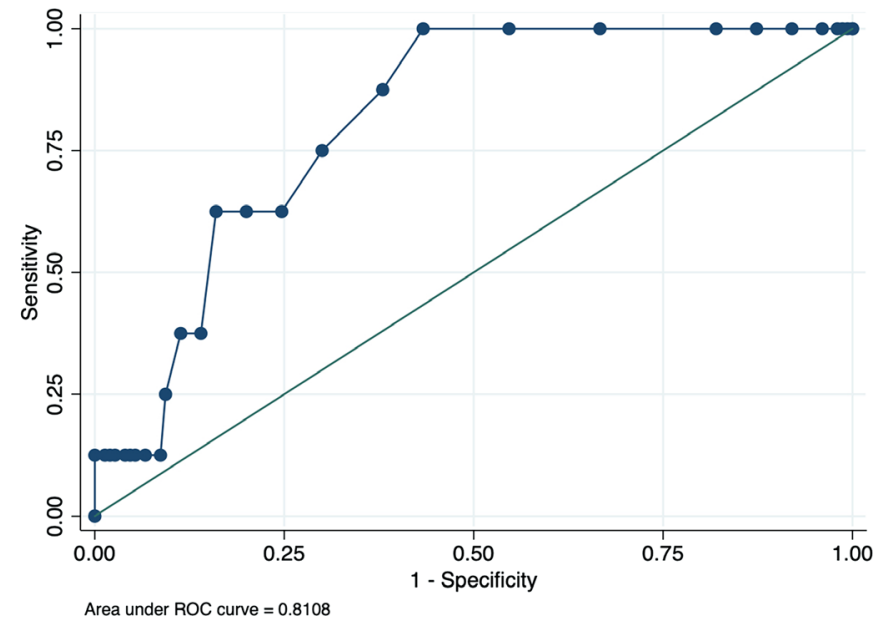

Figure 1. ROC curve of the sensitivity and 1-specificity of serum $\beta-2$ microglobulin levels in the prediction of metastatic disease in breast cancer. ROC, receiver operating characteristic.

differences in $\beta 2-\mathrm{M}$ levels were found to be associated with age, histologic type, and metastatic status. As our data showed that serum $\beta 2-\mathrm{M}$ levels were correlated with age, the level was re-analyzed with age stratification. The association between $\beta 2-\mathrm{M}$ levels and metastatic status held true only in those aged $>55$ years (Table II).

To evaluate the correlation between serum $\beta 2-\mathrm{M}$ levels and the prediction of metastatic status in breast cancers, a receiver operating curve (ROC) was constructed, as shown in Fig. 1. The area under the curve (AUC) was 0.78. If a serum $\beta 2-\mathrm{M}$ level of $1.9 \mu \mathrm{g} / \mathrm{ml}$ was used as a cut-off, the sensitivity to diagnose the metastatic status was $87.5 \%$, the specificity was $65.0 \%$, and the diagnostic odds ratio was 2.47 . Details of the diagnostic value of $\beta 2-\mathrm{M}$ using different cut-off values are shown in Table SI. When the ROCs of $\beta 2-\mathrm{M}$ performance for diagnosing metastasis were replotted by age subgroup, the AUC of the group of age 25-to 55-year-old group and the $>55$-year-old group were 0.75 (logistic regression P-value 0.22 ) and 0.82 (P-value 0.03), respectively. Median follow-up duration was 27.8 months and 24-month OS in all cases was $95.7 \%$. Two-year overall survival (2-year OS) analysis was performed by cancer types, stages, and $\beta 2-\mathrm{M}$ levels. The results showed that no significance of difference was found in 2-years OS when patients were sub-grouped by cancer types $(\log$ rank P-value=0.07) (Fig. 2A). However, when sub-grouping by stage of cancer, the significance of 2-year OS was found with the percentage of 96.4, 99.0, 88.2 and
$75.0 \%$ for stages I-III and IV, respectively (log rank P-value $<0.01$ ) (Fig. 2B). Two-year OS in cases with serum $\beta 2-\mathrm{M}$ levels lower than $1.9 \mu \mathrm{g} / \mathrm{ml}(98.3 \%)$ was also significantly higher than that of high serum $\beta 2-\mathrm{M}(89.3 \%, \log$ rank P-value $<0.01$ ) (Fig. 2C).

$\beta 2-M$ promoted migration ability of human breast cancer cell line. To study the influence of $\beta 2-\mathrm{M}$ on the metastatic capability of breast cancer, the low migratory MCF-7 cell line was subjected to the Transwell cell migration assay. Cells were treated with human recombinant $\beta 2-\mathrm{M}$ at different concentrations and incubated for $72 \mathrm{~h}$. The results revealed that ectopic treatment with $\beta 2-\mathrm{M}$ stimulated MCF-7 breast cancer cell migration, especially at $30 \mu \mathrm{g} / \mathrm{ml}$, and that the number of migrated cells was decreased at lower concentrations (Fig. 3). These findings indicated that $\beta 2-\mathrm{M}$ had a direct functional effect on MCF-7 cell movement.

\section{Discussion}

Human leukocyte antigen (HLA) consists of a heavy chain containing the alpha1, 2 and 3 domains and a light chain, which is a linked form of $\beta 2-\mathrm{M}$. $\beta 2-\mathrm{M}$ can be dissociated from HLA molecules and found as a free form in extracellular fluid and can also be detected in the blood $(27,28)$. Generally, the levels of $\beta 2-\mathrm{M}$ is directly dependent on the kidney's function and cell turnover rate; however, some studies have found correlation between the serum level of this protein and several cancers (29). The association between female breast cancer and tissue expression $\beta 2-\mathrm{M}$ has been observed in previous reports $(22,23)$. Higher serum $\beta 2-\mathrm{M}$ in breast cancer patients has been reported since 1977 by Transdale and colleagues (30). The mean serum $\beta 2-\mathrm{M}$ in our cases was lower than that reported by Teasdale. Interlaboratory variation may explain this disparity. Our main findings of an association between high serum $\beta 2-\mathrm{M}$ levels and metastatic status in breast cancer were consistent with recent studies which reported higher serum $\beta 2-\mathrm{M}$ levels in metastatic breast cancer patients than in those with early-stage or locally advanced diseases (31). In addition, our study also provided the suggested cut-off value of $\beta 2-\mathrm{M}$ at $1.9 \mu \mathrm{g} / \mathrm{ml}$ that might predict metastatic status and also demonstrated poorer survival probability in patients with high serum $\beta 2-\mathrm{M}$.

Roles of $\beta 2-\mathrm{M}$ in the promotion of the epithelial to mesenchymal transition (EMT) in cancers, which is the key scenario in cancer metastasis have been reported (32). Overexpression of $\beta 2-\mathrm{M}$ in cancers induces the invasion and migration ability of breast, lung, and renal cancer cell lines (33). In addition, $\beta 2-\mathrm{M}$ induces bone and soft tissue metastasis in mice, and 
A

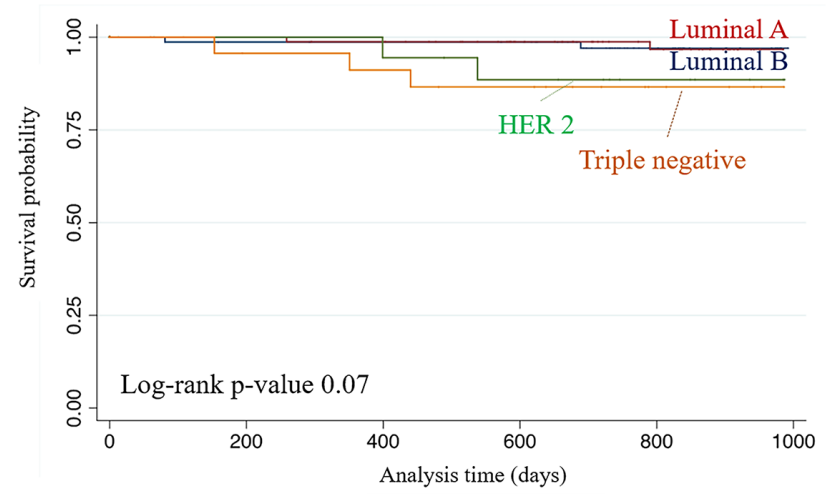

B

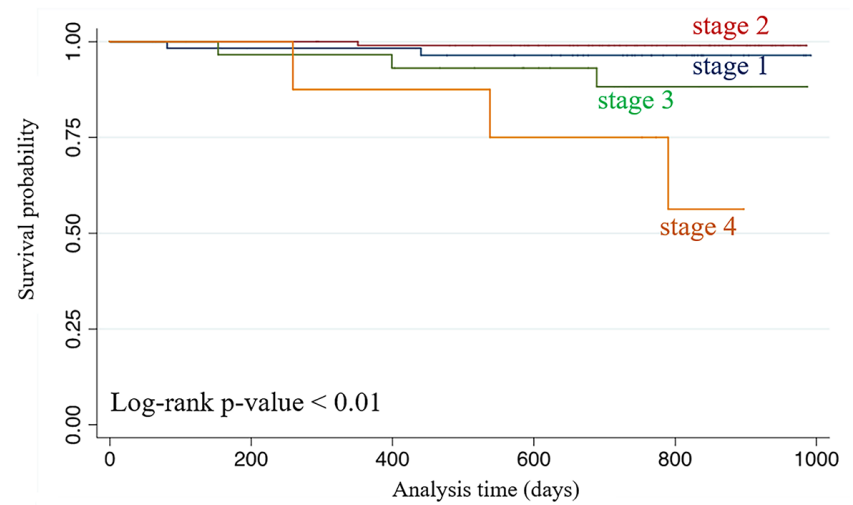

C

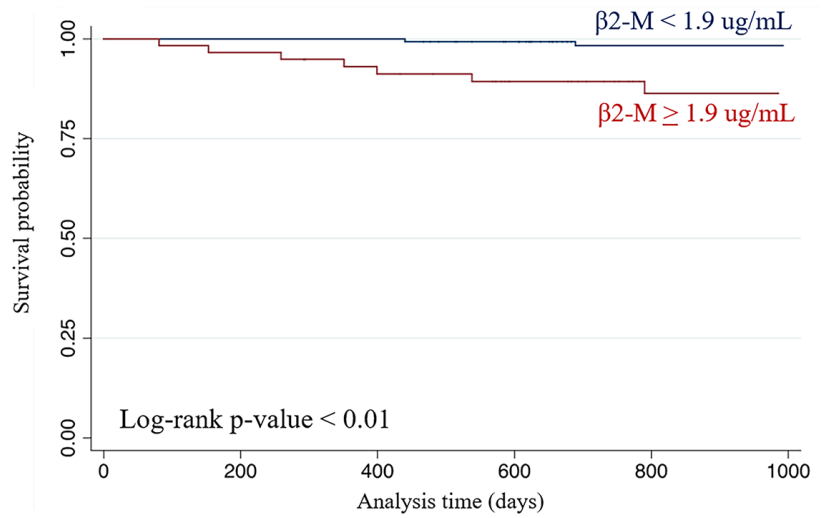

Figure 2. Kaplan-Meier curves comparing survival probability. (A) Overall survival according to the intrinsic subtype. (B) Overall survival according to stage grouping. (C) overall survival according to serum $\beta 2-\mathrm{M}$ levels. $\beta 2-\mathrm{M}$, $\beta-2$ microglobulin.

it can be used as a therapeutic target $(29,33)$. This evidence supports our findings and recent studies reporting high serum levels of $\beta 2-\mathrm{M}$ in cancer patients with distant metastasis (34). In accordance with our results, when poorly migrating cancer cells were exposed to high levels of recombinant $\beta 2-\mathrm{M}$, a higher migration ability was observed. This finding supports the role of $\beta 2-\mathrm{M}$ in promoting cancer cell metastasis. However, the detailed mechanism of $\beta 2-\mathrm{M}$ in cancer metastasis should be further evaluated. Our data suggested that serum $\beta 2-\mathrm{M}$ might be used as a marker for advanced disease at the time of diagnosis or during post-treatment follow-up.

Another consideration is that our data showed that serum $\beta 2-\mathrm{M}$ levels significantly varied with age, which may be

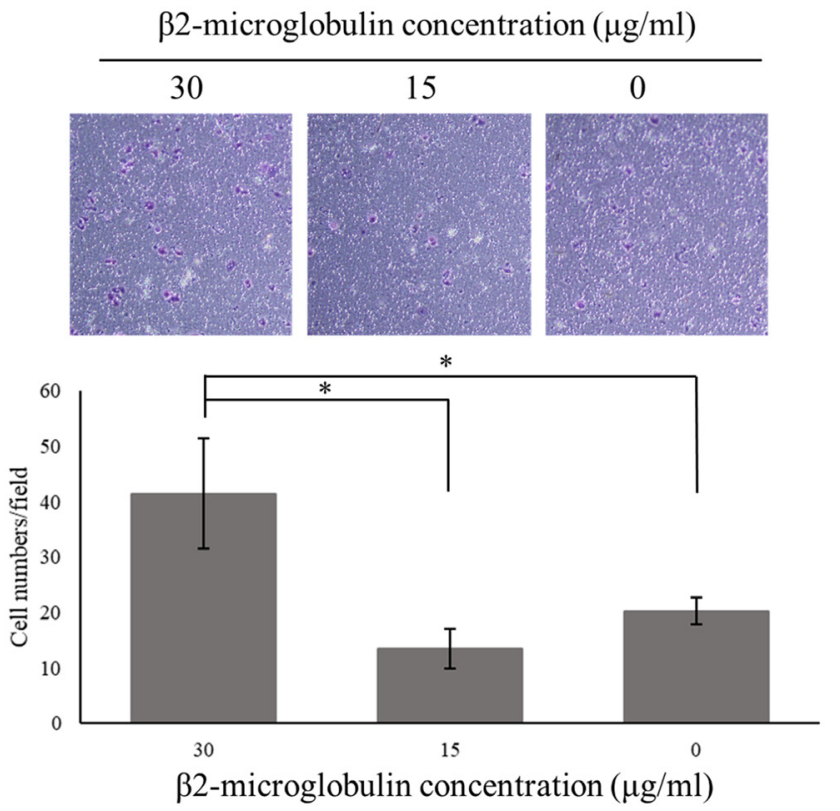

Figure 3. Transwell migration assay of MCF-7 cells treated with $\beta 2$-microglobulin at different concentrations. The upper panel shows a representative microscopic view (magnification, $\mathrm{x} 200$ ) of the migrating cells that reached the lower chamber. The lower panel shows the migrating cell numbers/field. The number in the $30 \mu \mathrm{g} / \mathrm{ml}$ group was significantly higher than those in the group treated with a lower concentration $(15 \mu \mathrm{g} / \mathrm{ml})$ and the no treatment control. ${ }^{*} \mathrm{P}<0.05$.

related to the fact that $\beta 2-\mathrm{M}$ excretion decreases with a reduction in glomerular filtration rate in the elderly. This same physiological process may explain the significant association between the serum $\beta 2-\mathrm{M}$ level and metastasis in the group of patients aged $>55$ years but not in the younger patients. Intact renal function and rapid clearance of $\beta 2-\mathrm{M}$ from the circulation results in less exposure of cancer cells to this migration-promoting substance. The limitations of our study were its cross-sectional design; in which no chronological data on alteration of $\beta 2-\mathrm{M}$ level can be analyzed. However, our data was consistent with a previous study in that patients with metastatic breast cancer and high $\beta 2-\mathrm{M}$ significantly had poorer survival (35).

In conclusion, serum $\beta 2-\mathrm{M}$ levels were significantly higher in women with metastatic breast cancer than in those with cancer of less advanced stages. In addition, the high level was correlated with poorer survival outcome. Serum $\beta 2-\mathrm{M}$ may be a non-invasive marker of metastatic status in breast cancer, and the cut-off level of 1.9-2.0 $\mu \mathrm{g} / \mathrm{ml}$ might be used for metastatic prediction with a greater than $85 \%$ sensitivity.

\section{Acknowledgements}

The authors would like to thank Mr. David Patterson of the International Affairs Office, Faculty of Medicine, Prince of Songkla University (Hat Yai, Songkhla, Thailand) for manuscript proofreading and language editing.

\section{Funding}

This research was supported and funded by the Faculty of Medicine, Prince of Songkla University (grant no. REC 
60-040-010-1) with postdoctoral fellowship program of the Faculty of Medicine, Prince of Songkla University.

\section{Availability of data and materials}

The datasets used and/or analyzed during the current study are available from the corresponding author on reasonable request.

\section{Authors' contributions}

SM and SSan conceived the study. SJ, SM, SSam, KK, JS and SSan developed the methodology. SSan provide software. SM and SSan validated the data. SJ, SSan, JS and SM performed formal analysis. SJ, KK and JS performed investigations. SSam and KK provided resources. SJ, SSan and SM curated data. SJ and JS wrote the original draft. SSan and JS reviewed and edited the manuscript. SSan and SM visualized data. SM supervised the study. SM was the project administrator. SM acquired funding. The authenticity of all the raw data was confirmed by SSan and SM. All authors read and approved the final manuscript.

\section{Ethics approval and consent to participate}

The board of The Human Research Ethics Committee of Faculty of Medicine, Prince of Songkla University approved the study protocol (reference no. 60-040-10-1; Hat Yai, Songkhla, Thailand). Written informed consent was obtained at the time of original sample collection.

\section{Patient consent for publication}

Not applicable.

\section{Competing interests}

The authors declare that they have no competing interests.

\section{References}

1. Fidler MM, Gupta S, Soerjomataram I, Ferlay J, SteliarovaFoucher E and Bray F: Cancer incidence and mortality among young adults aged 20-39 years worldwide in 2012: A populationbased study. Lancet Oncol 18: 1579-1589, 2017.

2. Forman D, Bray F, Brewster DH, Gombe MC, Kohler B, Piñeros M, Steliarova-Foucher E, Swaminathan R and Ferlay J (eds): Cancer incidence in five continents. Vol. 10 (electronic version). IARC Scientific Publications No. 164. International Agency for Research on Cancer, Lyon, 2013.

3. Parada H Jr, Sun X, Tse CK, Olshan AF and Troester MA: Lifestyle patterns and survival following breast cancer in the carolina breast cancer study. Epidemiology 30: 83-92, 2019.

4. Alkabban FM and Ferguson T: Breast cancer. In: StatPearls. StatPearls Publishing, Treasure Island (FL), 2020.

5. Imsamran W, Chaiwerawattana A, Wiangnon S, Pongnikorn D, Suwanrungrung K, Sangrajrang S and Buasom R: Cancer in Thailand. Vol. 8, 2010-2012. New Thammada Press (Thailand) Co., Ltd., 2015.

6. Park S, Koo JS, Kim MS, Park HS, Lee JS, Lee JS, Kim SI and Park BW: Characteristics and outcomes according to molecular subtypes of breast cancer as classified by a panel of four biomarkers using immunohistochemistry. Breast 21: 50-57, 2012

7. Grey HM, Kubo RT, Colon SM, Poulik MD, Cresswell P, Springer T, Turner M and Strominger JL: The small subunit of HL-A antigens is beta 2-microglobulin. J Exp Med 138: 1608-1612, 1973.
8. Cresswell P, Springer T, Strominger JL, Turner MJ, Grey HM and Kubo RT: Immunological identity of the small subunit of HL-A antigens and beta2-microglobulin and its turnover on the cell membrane. Proc Natl Acad Sci USA 71: 2123-2127, 1974.

9. Karlsson FA, Groth T, Sege K, Wibell L and Peterson PA: Turnover in humans of beta 2-microglobulin: The constant chain of HLA-antigens. Eur J Clin Invest 10: 293-300, 1980.

10. Karlsson FA, Wibell L and Evrin PE: Beta 2-microglobulin in clinical medicine. Scand J Clin Lab Invest Suppl 154: 27-37, 1980.

11. Hofstra JM, Deegens JK, Willems HL and Wetzels JF: Beta-2microglobulin is superior to $\mathrm{N}$-acetyl-beta-glucosaminidase in predicting prognosis in idiopathic membranous nephropathy. Nephrol Dial Transplant 23: 2546-2551, 2008.

12. Nozue T, Michishita I and Mizuguchi I: Predictive value of serum cystatin $\mathrm{C}, \beta 2$-microglobulin, and urinary liver-type fatty acid-binding protein on the development of contrast-induced nephropathy. Cardiovasc Interv Ther 25: 85-90, 2010.

13. Diem H, Fateh-Moghadam A and Lamerz R: Prognostic factors in multiple myeloma: Role of beta 2-microglobulin and thymidine kinase. Clin Investig 71: 918-923, 1993.

14. Musarurwa $\mathrm{C}$ and Matarira HT: Beta-2-microglobulin in multiple myeloma. Cent Afr J Med 50: 19-20, 2004.

15. Vassilakopoulos TP, Nadali G, Angelopoulou MK, Dimopoulou MN, Siakantaris MP, Kontopidou FN, Karkantaris C, Kokoris SI, Dimitriadou EM, Calpadaki C, et al: Beta(2)-microglobulin in Hodgkin's lymphoma: Prognostic significance in patients treated with ABVD or equivalent regimens. J BUON 10: 59-69, 2005.

16. Berrebi A, Bassous L, Haran M, Shtalrid M and Shvidel L: The significance of elevated beta 2-microglobulin (b2-m) in chronic lymphocytic leukemia (CLL): Evidence of in vitro secretion following activation of CLL cells. Leuk Res 34: e248-e249, 2010.

17. Vassilakopoulos TP,NadaliG,Angelopoulou MK,Siakantaris MP, Dimopoulou MN, Kontopidou FN, Karkantaris C, Kokoris SI, Kyrtsonis MC, Tsaftaridis $\mathrm{P}$, et al: The prognostic significance of beta(2)-microglobulin in patients with Hodgkin's lymphoma. Haematologica 87: 701-708, 2002.

18. Tsimberidou AM, Kantarjian HM, Wen S, O'Brien S, Cortes J, Wierda WG, Koller C, Pierce S, Brandt M, Freireich EJ, et al: The prognostic significance of serum beta 2 microglobulin levels in acute myeloid leukemia and prognostic scores predicting survival: Analysis of 1,180 patients. Clin Cancer Res 14: 721-730, 2008.

19. Durie BG, Stock-Novack D, Salmon SE, Finley P, Beckord J, Crowley J and Coltman CA: Prognostic value of pretreatment serum beta 2 microglobulin in myeloma: A Southwest oncology group study. Blood 75: 823-830, 1990.

20. Papaioannou D, Geggie P and Klassen J: Study of serum beta-2 microglobulin levels in breast cancer patients. Clin Chim Acta 99: 37-41, 1979.

21. Klein B, Levin I, Kfir B, Mishaeli M, Shapira J and Klein T: The significance of soluble interleukin-2, soluble interleukin-2 receptors, soluble ICAM-1 and beta 2-microglobulin in breast cancer patients. Tumour Biol 16: 290-296, 1995.

22. Li K, Du H, Lian X, Yang S, Chai D, Wang C, Yang R and Chen $X$ : Characterization of $\beta 2$-microglobulin expression in different types of breast cancer. BMC Cancer 14: 750, 2014.

23. Chai D, Li K, Du H, Yang S, Yang R, Xu Y and Lian X: 32 -microglobulin has a different regulatory molecular mechanism between $\mathrm{ER}^{+}$and $\mathrm{ER}^{-}$breast cancer with HER2. BMC Cancer 19: 223, 2019.

24. Tsuda H, Hirohashi S, Higuchi K and Shimosato Y: Beta2-microglobulin expression in relation to amplification of oncogenes and prognosis in breast carcinoma. Histopathology 16: 500-502, 1990.

25. Zhou B, Xu L, Ye J, Xin L, Duan X and Liu Y: The prognostic value of the 8th edition of the American joint committee on cancer (AJCC) staging system in HER2-enriched subtype breast cancer, a retrospective analysis. Anticancer Res 37: 4615-4621, 2017.

26. Khaled H, Gamal H, Lotayef M, Knauer M and Thürliman B: The St. Gallen international expert consensus conference on the primary therapy of early breast cancer 2017: Egyptian view. Breast Cancer Res Treat 172: 545-550, 2018.

27. Wibell L: The serum level and urinary excretion of beta2-microglobulin in health and renal disease. Pathol Biol (Paris) 26: 295-301, 1978. 
28. Karlsson FA, Dahlberg PA, Venge P and Roxin LE: Serum myoglobin in thyroid disease. Acta Endocrinol (Copenh) 94: 184-187, 1980.

29. Shi C,Zhu Y, Su Y, Chung LW and Cheng T: Beta2-microglobulin: Emerging as a promising cancer therapeutic target. Drug Discov Today 14: 25-30, 2009.

30. Teasdale C, Mander AM, Fifield R, Keyser JW, Newcombe RG and Hughes LE: Serum beta2-microglobulin in controls and cancer patients. Clin Chim Acta 78: 135-143, 1977.

31. Petekkaya I, Aksoy S, Roach EC, Okoh AK, Gecmez G, Gezgen G, Isler DC, Dogan E, Babacan T, Sarici F, et al: Impact of inflammatory markers on the prognosis of patients with operable breast cancer. J BUON 19: 673-680, 2014.

32. Lamouille S, Xu J and Derynck R: Molecular mechanisms of epithelial-mesenchymal transition. Nat Rev Mol Cell Biol 15: 178-196, 2014.
33. Josson S, Nomura T, Lin JT, Huang WC, Wu D, Zhau HE, Zayzafoon M, Weizmann MN, Gururajan M and Chung LW: 32-Microglobulin induces epithelial to mesenchymal transition and confers cancer lethality and bone metastasis in human cancer cells. Cancer Res 71: 2600-2610, 2011.

34. Chen CH, Su CY, Chien CY, Huang CC, Chuang HC, Fang FM, Huang HY, Chen CM and Chiou SJ: Overexpression of beta2-microglobulin is associated with poor survival in patients with oral cavity squamous cell carcinoma and contributes to oral cancer cell migration and invasion. Br J Cancer 99: 1453-1461, 2008.

35. Petekkaya I, Unlu O, Roach EC, Gecmez G, Okoh AK, Babacan T, Sarici F, Keskin O, Arslan C, Petekkaya E, et al: Prognostic role of inflammatory biomarkers in metastatic breast cancer. J BUON 22: 614-622, 2017 